\title{
A POSSIBILIDADE DE DEDUÇÃO DO PASSIVO AMBIENTAL NA DESAPROPRIAÇÃO POR DESCUMPRIMENTO DA FUNÇÃO SOCIOAMBIENTAL DA PROPRIEDADE RURAL
}

\section{THE POSSIBILITY OF DEDUCTION OF ENVIRONMENTAL LIABILITIES IN EXPROPRIATION FOR EACH BREACH OF ENVIRONMENTAL RURAL PROPERTY}

\author{
${ }^{1}$ Ricardo Nasser Sefer \\ ${ }^{2}$ Felipe Jales Rodrigues
}

\section{RESUMO}

O presente trabalho visa abordar a possibilidade de dedução do passivo ambiental do quantum da indenização mensurada na desapropriação de propriedade rural que descumpriu sua função socioambiental. Nesse viés, a Constituição Federal de 1988, previu a possibilidade de desapropriar o imóvel rural que descumpriu sua função socioambiental. Dessa previsão, diante da existência de um passivo ambiental, há premência necessidade /possibilidade de se deduzir esse passivo, ante a exigência constitucional da prévia e justa indenização. Sobre o assunto, o Tribunal Regional Federal da $1^{\mathrm{a}}$ Região ainda não firmou jurisprudência, gerando, como consequência, insegurança jurídica aos proprietários de terra e à própria comunidade.

Palavras-chave: Desenvolvimento sustentável, Função socioambiental, Passivo ambiental, Justa indenização

\begin{abstract}
This study aims to address the deductibility of environmental liability indemnification of quantum measured in the expropriation of rural property that failed to fulfill its environmental function. The Federal Constitution of 1988, provided for the possibility to expropriate rural property that failed to comply with its social and environmental role. On the subject, the Federal Regional Court of the 1st Region does not signed a single position on this opportunity to deduct the environmental liability, generating as a result, legal uncertainty for landowners and the community itself, being the Institute of Colonization and Agrarian Reform - INCRA the correct deduction.
\end{abstract}

Keywords: Sustainable development, Environmental function, Environmental liability, Fair indemnity

\footnotetext{
${ }^{1}$ Doutor em Direito pela Universidade Federal do Pará - UFPA, Pará (Brasil). Professor da Universidade da Amazônia - UNAMA, Amazonas (Brasil). E-mail: rsefer@bol.com.br

${ }^{2}$ Mestrando do Programa de Pós-Graduação da Universidade Federal do Pará - UFPA, Pará (Brasil). E-mail: felipejales@hotmail.com
} 


\section{INTRODUÇÃO}

O tema proposto para o presente trabalho é a discussão acerca da possibilidade de dedução do passivo ambiental na desapropriação por descumprimento da função socioambiental da propriedade rural, tendo como problema o debate acerca da existência de base jurídica para realizar tal abatimento.

Tendo em vista que a problemática ambiental tornou-se um dos temas mais comentados dos últimos anos, verifica-se o aumento progressivo da preocupação do ser humano com a questão da preservação ambiental, criando e se utilizando de instrumentos jurídicos que possam proteger, efetiva e eficazmente, o meio ambiente.

A abordagem iniciará com o estudo da desapropriação como instrumento de controle do Estado, demonstrando como o Poder Público atua sobre a propriedade privada em casos de descumprimento da função socioambiental desse imóvel rural, discutindo sobre a justa indenização pela desapropriação. Na seção seguinte, será discutida a teoria do passivo ambiental, abordando seu conceito e sua incidência na desapropriação da propriedade rural, ressaltando a posição do Instituto de Colonização e Reforma Agrária - INCRA, do Tribunal de Contas da União e os julgados divergentes do Tribunal Regional Federal da Primeira Região sobre a possibilidade de dedução do passivo na indenização respectiva, além de traçar o entendimento do Superior Tribunal de Justiça quanto ao tema proposto.

Optou-se por tratar diretamente acerca das decisões do TRF-1 ${ }^{a}$ Região, em razão de que essa Corte tem competência sobre todos os Estados que compõem a Região Norte do país, os quais abrigam, na maioria de seus territórios, a denominada Amazônia Legal, terra constitucionalmente tutelada por nosso ordenamento jurídico pátrio.

Destaca-se que a responsabilidade civil por danos ao meio ambiente, prevista na Lei 6.938/1981, artigo $14, \S 1^{\circ}$, é objetiva, não dependendo, portanto, da existência de culpa, sendo defendia pela maioria da doutrina nacional que essa responsabilidade dá-se na modalidade "risco integral", ou seja, não admite hipóteses de excludente do nexo causal.

Ademais, um dano causado ao meio ambiente dentro de uma propriedade rural se transmite ao comprador desse imóvel, e, por conseguinte, a obrigação de recomposição daquela área afetada passa a ser do novo proprietário. Daí que se diz que a obrigação de recompor a cobertura vegetal é "Propter Rem", acompanha a coisa. 
Decorrente desse dano poderá ocorrer o descumprimento da Função Social da Propriedade prevista no artigo 186 da Constituição Federal e no artigo 9ª da Lei 8.629/1993, os quais preceituam que a Função Social é cumprida quando atende a certos requisitos, quais sejam: aproveitamento racional e adequado, utilização adequada dos recursos naturais disponíveis e a preservação do Meio Ambiente, observância das disposições que regulam as relações de trabalho e exploração que favoreça o bem estar dos proprietários e dos trabalhadores.

Para essa discussão, interessam os dois primeiros requisitos referentes à Função Social da propriedade, os quais tratam da questão ambiental, deixando claro que sua função não se restringe mais somente aos níveis de produção, senão a preservação ambiental.

Portanto, partindo da desapropriação por descumprimento da função social pelo viés ambiental da propriedade rural, há que se falar na justa indenização por essa medida administrativa, vez que a própria Constituição Federal, no artigo 184 e seguintes, prevê a justa e prévia indenização ao proprietário pela destituição de seu bem imóvel.

De tal maneira, o Direito Agroambiental utiliza-se de um conceito que representa a obrigação de reparar a degradação ambiental a partir dos danos causados pelas atividades humanas: o passivo ambiental. Esse nada mais é do que os danos causados no Meio Ambiente pelo empreendedor, os quais lhe obrigam a recuperar a área danificada a partir de sua responsabilidade.

Ainda sobre o tema, é de se afirmar que a direta relação existente entre o passivo ambiental e a preocupação do ser humano com o meio ambiente, constata-se que os princípios de proteção previstos pelo Direito Ambiental incidem diretamente sobre a ocorrência de um dano ao ambiente, e, por conseguinte, ao passivo ambiental.

Como se pode perceber, o passivo ambiental poderá decorrer, então, de um dano ambiental, vez que não há degradação ambiental e, por conseguinte, obrigação de repará-lo, sem antes haver uma lesão ao bem jurídico ambiental. Por outro lado, sua existência poderá se dar, também, por atos de cunho positivo do proprietário.

Diante dessa discussão, pode-se afirmar que havendo descumprimento da função socioambiental da propriedade rural, o imóvel poderá sofrer a sanção da desapropriação, desde que haja a prévia e justa indenização, nos termos do artigo 184 da Constituição Federal e do artigo $5^{\circ}$ da Lei 8.629/1993. 
Em obediência ao princípio da justa indenização, previsto desde 1934 (art. 113, XVII) na ordem constitucional brasileira, há necessidade de se considerar a dedução do passivo ambiental na desapropriação por descumprimento da função ambiental da propriedade rural.

Eis os contornos da questão jurídica objeto da presente análise.

\section{A DESAPROPRIAÇÃO COMO INSTRUMENTO DE CONTROLE DO ESTADO E A FUNÇÃO SOCIOAMBIENTAL DA PROPRIEDADE.}

Sabe-se que a responsabilização de quem causou o dano ambiental é integral, conforme ampla doutrina especializada ${ }^{1}$, não admitindo, portanto, excludentes do nexo causal, tais como: força maior, caso fortuito, fato de terceiro etc. o que atesta a gande preocupação do legislador com a definição de rígidas normas de proteção ao meio ambiente.

Dessa maneira, destaca-se que uma obrigação propter rem é aquela que adere ao bem, transferindo-se em conjunto com a propriedade, aderindo-se ao imóvel, independente da figura do proprietário. Sendo assim, um dano ambiental gera ao poluidor o dever de reparar integralmente, conforme entendimento dominante no STJ, o qual, no julgamento dos recentes fixou o entendimento de que um dano ambiental deve ser reparado integralmente a área degradada ${ }^{2}$.

Para efeitos de equiparação ao poluidor, para apuração do nexo de causalidade, será todo aquele quem faz, quem não faz quando deveria fazer, quem deixa de fazer, quem não se importa que façam, quem financia para que façam, e quem se beneficia quando outros fazem, conforme julgamento do Recurso Especial 650.728/SC ${ }^{3}$.

Nessa esteira de pensamento, está pacificado em nossos Tribunais que a responsabilidade civil pela reparação dos danos ambientais adere à propriedade, como

\footnotetext{
${ }^{1}$ SILVA, José Afonso da, 2003. Pag. 313; NERY JÚNIOR, Nelson. A responsabilidade civil por dano ecológico e a Ação Civil Pública. Ed. Justitia, Pag. 126/170; CAVALIERI FILHO, 200. Pag. 153-154.

${ }^{2}$ REsp 1382999/SC, Rel. Ministro HUMBERTO MARTINS, SEGUNDA TURMA, julgado em 19/08/2014, DJe 18/09/2014; REsp 1307938/GO, Rel. Ministro BENEDITO GONÇALVES, PRIMEIRA TURMA, julgado em 16/06/2014, DJe 16/09/2014.

3 REsp 650.728/SC, Rel. Ministro HERMAN BENJAMIN, SEGUNDA TURMA, julgado em 23/10/2007, DJe 02/12/2009. Disponível em: http://www.stj.jus.br/SCON/jurisprudencia/toc.jsp?i=1\&b=ACOR\&livre=\%28\%28\%27RESP $\% 27$. clas.+e +@ num $=\% 27650728 \% 27 \% 29+\mathrm{ou}+\% 28 \% 27 \mathrm{RESP} \% 27+\mathrm{adj}+\% 27650728 \% 27$. suce $\% 29 \% 29 \&$ thesaurus= JURIDICO. Acesso em: 07/12/2015.
} 
obrigação propter rem, sendo possível também cobrar do atual proprietário condutas derivadas de danos provocados pelos antigos proprietários de determinado imóvel ${ }^{4}$.

Por outro lado, a desapropriação por descumprimento da função socioambiental da propriedade rural é meio pelo qual o Estado toma a propriedade para si, desde que aquele imóvel rural não tenha cumprido a sua Função Social, conforme leitura do artigo 186 da Constituição Federal, o qual estipula as condições que a propriedade deve atender para cumprir sua função social, quais sejam: o aproveitamento racional e adequado; a utilização dos recursos naturais disponíveis e preservação do meio ambiente; observância das relações de trabalho; e a exploração que favoreça o bem estar dos proprietários e dos trabalhadores.

Nesse sentido, Silvia Opitz e Oswaldo Opitz ${ }^{5}$ sustentam que:

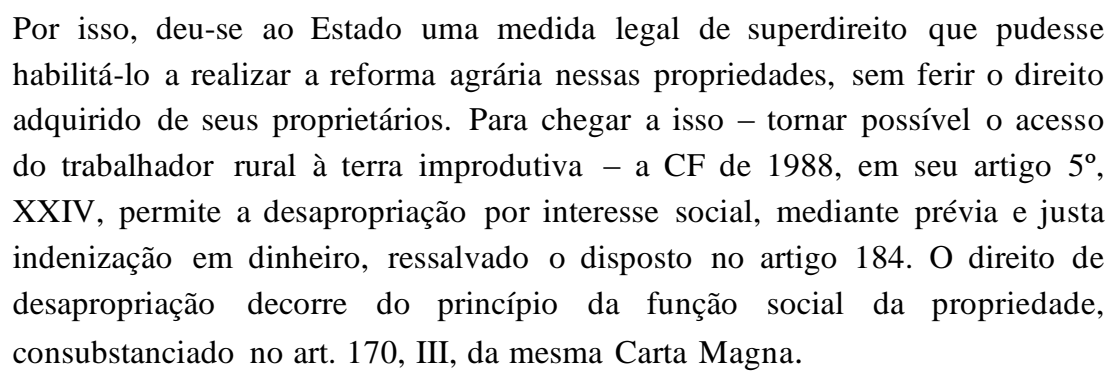

Ademais, a Lei 8.629, de 25 de fevereiro de 1993, a partir da inteligência do artigo $2^{\circ}$, há previsão expressa de que a propriedade que não cumprir sua função social é passível de desapropriação, estipulando, inclusive, em uma clara cópia da Constituição, os seus critérios de cumprimento.

A função socioambiental ou simplesmente função ambiental da propriedade rural $^{6}$ pode ser determinada para aquela propriedade que não observou os claros incisos I e II do artigo 186 da Constituição Federal, em conjunto com a regulamentação dada pela Lei 8.629, de 1993, sendo passível de sofrer a desapropriação para fins de reforma agrária.

\footnotetext{
${ }^{4}$ REsp 1251697/PR, Rel. Ministro MAURO CAMPBELL MARQUES, SEGUNDA TURMA, julgado em 12/04/2012, DJe 17/04/2012. Disponível em: http://www.stj.jus.br/SCON/jurisprudencia/toc.jsp?i=1\&b=ACOR\&livre=\%28\%28\%27RESP\%27.clas.+e $+@$ num $=\% 271251697 \% 27 \% 29+$ ou+\%28\%27RESP $\% 27+$ adj+\%271251697\%27.suce.\%29\%29\&thesauru s=JURIDICO. Acessado em: 07/12/2015.

${ }^{5}$ OPITZ, Silvia C. B; OPITZ, Oswaldo C. B. Curso Completo de Direito Agrário. São Paulo: Editora Saraiva, 2011. P. 198.

"BORGES, Roxana Cardoso Brasileiro, "Função ambiental da propriedade e reforma agrária", in SILVEIRA, Domingos Sávio Dresch; XAVIER, Flávio Sant’Anna. O Direito Agrário em debate. Porto Alegre: Editora Livraria do Advogado, 1998.
} 
Nas palavras de Roxana C. B. Borges ${ }^{7}$ :

Portanto, a propriedade cuja exploração não respeita a vocação natural da
terra, degradando o seu potencial produtivo, que não mantém as
características próprias do meio natural, que agride a qualidade dos recursos
ambientais, não contribuindo para a manutenção do equilíbrio ecológico da
propriedade, nem é adequada à saúde e à qualidade de vida das comunidades
vizinhas está sujeita a sofrer a desapropriação.

Portanto, não basta tão somente que a propriedade rural seja improdutiva, ela deve atender a critérios satisfatórios de preservação ambiental, conjuntamente com critérios de produção que torne esse imóvel rural produtivo aos "olhos" da lei.

Em artigo publicado, o ilustre Paulo Roberto Lyrio Pimenta ${ }^{8}$ afirma que: “...exploração da propriedade agrária, causando danos ao meio ambiente, implicará no descumprimento da sua função social, dando ensejo à desapropriação por interesse social".

Nessa esteira de raciocínio, não há dúvidas de que o descumprimento da função ambiental da propriedade rural poderá fazer reclamar a incidência do instrumento da desapropriação, em cumprimento ao que determina o artigo 184 da Constituição Federal, o qual prevê a desapropriação por interesse social, para fins de reforma agrária, do imóvel rural que não esteja cumprindo sua função social, mediante prévia e justa indenização.

Ressalta-se que precede à desapropriação do imóvel rural que descumpriu sua função social a prévia e justa indenização, constituindo-se uma forma encontrada pelo legislador de compensar a retirada da propriedade do âmbito particular e incorporando ao patrimônio estatal para futura destinação social.

A indenização compensatória, prevista no artigo 184 da Constituição Federal, encontrando regulamentação no artigo $5^{\circ}$, da Lei 8.629, de 25 de fevereiro de 1993, o qual parâmetros para o cumprimento da obrigação de indenização prévia e justa do imóvel rural, que deverá observar aspectos como: a localização do bem, a sua aptidão

\footnotetext{
${ }^{7}$ Idem. P. 308.

${ }^{8}$ PIMENTA, Paulo Roberto Lyrio. “A função social da propriedade agrária e os interesses difusos". In PIMENTA, Paulo Roberto Lyrio, DIAS, Sérgio Novaes. Revista dos Mestrandos em Direito Econômico da UFBA. Salvador: UFBA, 1995. P. 174.
} 
agrícola, a dimensão do imóvel, a área ocupada, assim como o estado de conservação das benfeitorias, entre outros ${ }^{9}$.

De tal modo, faz-se necessária a indenização justa e prévia à conclusão do processo de desapropriação do imóvel. O juízo de justiça na indenização deverá ser aquele previsto no artigo 12 da Lei 8.629/1993, in verbis:

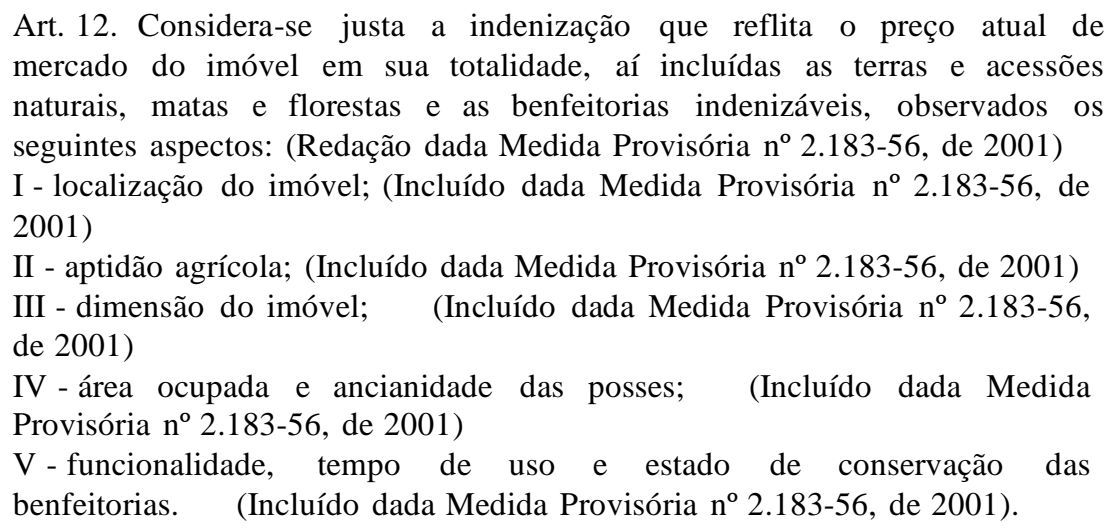

Tal previsão deverá estar sempre em conformidade com os demais princípios que regem o Direito.

Partindo do pressuposto que a propriedade rural que descumpriu a função socioambiental da propriedade rural sofrerá a desapropriação pelo poder público, sob a justificativa de interesse social, e ainda que haverá a indenização prévia e justa, cabe a questão se é possível a dedução do passivo ambiental nessa indenização.

\section{PASSIVO AMBIENTAL E A POSSIBILIDADE DE SUA DEDUÇÃo.}

Delineadas as discussões sobre o dano ambiental e as diversas formas de se responsabilizar o poluidor, traçando um parâmetro histórico do início da discussão para se tutelar o meio ambiente e se conscientizar de sua importância para a sociedade, com a criação e o amadurecimento do próprio conceito de desenvolvimento sustentável.

Demonstrado, ainda, o modelo legal para o Estado, enquanto Poder Público utilizar-se do instrumento da desapropriação como forma de controle sobre a propriedade particular para concretizar os ditames constitucionais acerca da necessidade de se realizar, efetiva e eficazmente, o cumprimento da função socioambiental da

\footnotetext{
${ }^{9}$ OPITZ, Silvia C. B; OPITZ, Oswaldo C. B. Curso Completo de Direito Agrário. São Paulo: Editora Saraiva, 2011. P. 213.
} 
propriedade rural, tendo-se em vista que o direito de propriedade não é mais considerado absoluto, já que o bem estar social se sobrepõe aos interesses particulares.

Chega-se a conclusão, pela viabilidade jurídica da desapropriação do imóvel rural a partir de práticas abusivas contra o meio ambiente e que utilizem descontroladamente os recursos naturais, configurando uma prática nociva à toda sociedade.

Nesse sentido, uma vez verificada a presença de passivo ambiental, o qual se configura na existência de qualquer tipo de dano a um determinado bem ambiental, surge a obrigação do proprietário em se responsabilizar por este, seja por intermédio da oposição da obrigação de fazer na recomposição do dano, seja através da obrigação de pagar para financiar tal recuperação.

Destaque-se a literatura das ciências contábeis a qual define o passivo ambiental é tão recente no mundo, quanto no Brasil, pelo que, estudiosos apontam que sua primeira utilização se deu em 1992, na Câmara Internacional do Comércio, na Holanda, definindo-se como e quando haverá obrigação presente por parte do proprietário ambiental em relação a eventos passados ${ }^{10}$.

Como bem salienta Ricardo Dias Sameshima e Sylvio Toshiro Mukai ${ }^{11}$ :

\begin{abstract}
A ideia de Passivo Ambiental foi retirada das Ciências Contábeis e estaria ligada ao conceito de dívida ou obrigações assumidas por uma determinada empresa. No caso específico do Direito Ambiental, ao tratarmos de Passivo Ambiental, estamos tratando das obrigações assumidas pelas empresas no tocante à reparação de danos ambientais, sejam eles fruto de condenações judiciais, sejam decorrentes de ajustamentos de condutas. Incorpora, ainda, as reparações de danos ambientais constatados posteriormente.
\end{abstract}

Sobre o tema, ainda, acrescenta Maria Elisabeth Pereira Kraemer ${ }^{12}$ :

Uma empresa tem Passivo Ambiental quando ela agride, de algum modo e/ou ação, o meio ambiente, e não dispõe de nenhum projeto para sua recuperação, aprovado oficialmente ou de sua própria decisão. Passivo Ambiental representa toda e qualquer obrigação de curto e longo prazo, destinadas única

10 FERREIRA (2006), REBOllo (2000) e CASTRO (2006) in FERNANDES, Sheila Mendes; SANTIAGO, Wagner de Paulo; PEIXOTO. Fernanda Maciel. Passivo ambiental: Um levantamento em empresas localizadas no Município de Montes Claros/MG. Prêmio Excelência Acadêmica. XII SemeAd. Empreendedorismo e Inovação. EAD. USP. 27 e 28 de agosto de 2009. Disponível em: http://www.fucape.br/premio_excelencia_academica/upld/trab/9/scheila.pdf. Acessado em: 23/08/2015.

${ }^{11}$ SAMESHIMA, Ricardo Dias; MUKAI, Sylvio Toshiro. Passivo ambiental: considerações. Fórum de Direito Urbano e Ambiental FDUA, Belo Horizonte, ano 2, n. 7, jan./fev. 2003. Disponível em: http://www.bidforum.com.br/bid/PDI0006. aspx?pdiCntd=10683. Acesso em: 19/08/2015.

12 KRAEMER, Maria Elisabeth Pereira. Passivo ambiental. Artigo publicado e disponível no site: http://www.amda.org.br/imgs/up/Artigo_21.pdf. Acessado em: 14/08/2015. 
e exclusivamente a promover investimentos em prol de ações relacionadas à extinção ou amenização dos danos causados ao meio ambiente, inclusive percentual do lucro do exercício, com destinação compulsória, direcionado a investimentos na área ambiental.

Dessa forma, nota-se que o passivo ambiental corresponde a todo dano suportado pelo poluidor, o qual se compromete a agir em prol da recuperação e recomposição dessa área danificada, visando, sobretudo, reparar integralmente o meio ambiente ou, pelo menos, compensar a coletividade pelos prejuízos causados.

O passivo, portanto, pode ser encontrado a partir do uso de uma área, lago, rio, mar ou uma série de espaços que compõem nosso meio ambiente, inclusive o ar que respiramos, ou ainda pelo processo de geração de resíduos ou lixos industriais, de difícil eliminação ${ }^{13}$.

Maria Elisabeth Pereira Kraemer ${ }^{14}$, em seu estudo aprofundado sobre o tema, divide as obrigações decorrentes do passivo ambiental em três patamares: (i) Obrigação Legal; (ii) Obrigação Construtiva; e (iii) Obrigação Justa.

A primeira decorre da obrigação assumida pelo proprietário, decorrente da celebração de um contrato, legislação ou outro instrumento legal, a partir de eventos passados com o uso do meio ambiente ou a geração de resíduos tóxicos.

Cita-se, como exemplo, uma empresa que utiliza determinado espaço e, para isso, resultado de sua atividade industrial, firma contratos com o Poder Público local, comprometendo-se a fazer o reaproveitamento do solo, com práticas benéficas ao meio ambiente.

De tal classificação, surge a obrigação implícita, que seria aquela na qual a empresa poluidora, a partir de compromissos assumidos diante do público local ou de declarações assumidas, legitima uma expectativa junto aos terceiros para cumprimento dessa obrigação ambiental.

O segundo patamar, denominado construtivas, ocorre quando a própria empresa, por livre e espontânea vontade, assume os compromissos ambientais frente à população local, com o intuito de melhorar sua reputação diante do público, o mesmo para cumprir com suas políticas ambientais, demonstrando sua preocupação com o bem estar social.

O terceiro patamar no qual a autora trata são as obrigações Justas, ou seja, a empresa cumpre em razão de fatores éticos e morais. Neste caso, destaca-se o fato de

\footnotetext{
13 Idem.

${ }^{14}$ Idem.
} 
que uma empresa, quando perceber uma área contaminada na execução de suas atividades, em se tratando de fato público e notório, afetando direitos e interesses de terceiros, será compelida a reparar o erro cometido ${ }^{15}$.

De todo modo, os princípios norteadores das atividades ambientais, previstos em nosso ordenamento jurídico para tutelar o meio ambiente, relacionam-se diretamente com a existência do passivo ambiental, na medida em que (i) a preocupação dos envolvidos nessa relação resulta numa maior proteção aos recursos naturais - princípio ao meio ambiente ecologicamente equilibrado - compatibilizando com os ditames do desenvolvimento sustentável; (ii) as políticas de preservação e conservação do ambiente que norteiam toda a atividade empresarial são implementadas no sentido de se evitar o cometimento de qualquer tipo de prejuízo ambiental - princípio da prevenção e precaução; (iii) as empresas se responsabilizam pelos danos causados, investindo em pesquisa e projetos para recuperação de áreas degradadas - princípio do poluidor pagador; (iv) o Poder Público deverá fiscalizar e fazer cumprir a lei nas propriedades em que se verificar agressão ao meio ambiente, sem que haja a tomada das medidas legalmente previstas para se evitar ou mesmo minimizar os danos ambientais causados, impondo-se a aplicação da desapropriação nos casos legais - princípio da obrigatoriedade da atuação estatal e da Função Socioambiental da Propriedade.

De outra banda, ainda que se pense que o passivo ambiental é ocasionado somente pelas pequenas, médias e grandes empresas latifundiárias na execução de suas atividades fins, destaca-se que tal conceituação pode ser verificada na utilização da

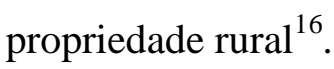

Dessa forma, independentemente da natureza do proprietário do imóvel rural, se pequena ou grande empresa, ou ainda pequenos ou grandes proprietários de terra, impõem-se o cumprimento da função socioambiental da propriedade rural, em atendimento aos princípios que norteiam essa relação com o meio ambiente, internalizando os custos da preservação ambiental, tendo em vista que a utilização da propriedade, nos dias atuais, deve atentar para o bem estar social, tanto para os presentes, quanto para as futuras gerações.

\footnotetext{
15 KRAEMER, Maria Elisabeth Pereira. Passivo Ambiental. Artigo publicado e disponível no site: http://www.amda.org.br/imgs/up/Artigo_21.pdf. Acessado em: 14/08/2015.

${ }^{16}$ SAMESHIMA, Ricardo Dias; MUKAI, Sylvio Toshiro. Passivo Ambiental: considerações. Fórum de Direito Urbano e Ambiental FDUA, Belo Horizonte, ano 2, n. 7, jan./fev. 2003. Disponível em: http://www.bidforum.com.br/bid/PDI0006. aspx?pdiCntd=10683. Acesso em: 19/08/2015.
} 
Desta feita, o reconhecimento de um passivo ambiental é realizado a partir das obrigações assumidas pela empresa, decorrente as atividades que realiza, contabilizando-o a partir dos danos ambientais causados, ou mesmo pelas ações positivas praticadas.

\begin{abstract}
Um passivo ambiental deve ser reconhecido quando existir uma obrigação por parte da empresa que incorreu em um custo ambiental ainda não desembolsado, desde que atenda ao critério de reconhecimento como uma obrigação. Portanto, esse tipo de passivo é definido como sendo uma obrigação da empresa que surgiu de eventos passados ${ }^{17}$.
\end{abstract}

Há autores, por sua vez, que afirmam que para se reconhecer um passivo ambiental, há a exigência de se conhecer o montante financeiro que será dispendido, pelo que, dependendo de cada caso, esse valor poderá ser superior à cobrança, ou a empresa possui parâmetros para estimá-lo, utilizando-se de cálculos aproximados para se reconhecê-lo ${ }^{18}$.

De outro modo, não será necessário conhecer o valor a posteriori ao dano, vez que, em atendimento aos princípios da precaução e prevenção, as empresas ou proprietários de terra têm o dever de prever os danos que poderão ser causados com as suas atividades, ou pelo menos implementar todos os esforço no sentido de evitá-los.

Coelho, Dutra e Cardoso ${ }^{19}$ afirmam que ambas as definições estão incompletas, tendo em vista que o conservadorismo obriga a adoção de um espírito de precaução por parte do contador, o que deve ser aplicado, necessariamente, na contabilidade ambiental que deve reconhecer o dano antes de sua efetivação.

Tais autores sustentam que há três momentos para se reconhecer o passivo ambiental: (i) com a possibilidade de se reconhecer o evento antes do impacto; (ii) no momento em que a empresa percebe a ocorrência do dano; (iii) quando as consequências do impacto ambiental são sentidos pela empresa e pela comunidade ${ }^{20}$.

17 KRAEMER, Maria Elisabeth Pereira. Passivo Ambiental. Artigo publicado e disponível no site: http://www.amda.org.br/imgs/up/Artigo_21.pdf. Acessado em: 14/08/2015.

${ }^{18}$ RIBEIRO E LISBOA,SOUZA, Maísa de ; PLACIDO,Lázaro. Passivo Ambiental.Revista Brasileira de Contabilidade: trabalhos técnicos premiados no XVI CBC, ano XXIX, n ${ }^{\circ} 126$, novembro/dezembro 2000.

${ }^{19}$ COELHO, Dutra, et al.. Evidenciação do investimento no social e no ambiental. Revista Pensar Contábil ano III, $\mathrm{n}^{\circ} 09$ agosto/outubro de 2000. In FERREIRA (2006), REBOLLO (2000) e CASTRO (2006) in FERNANDES, Sheila Mendes; SANTIAGO, Wagner de Paulo; PEIXOTO. Fernanda Maciel. Passivo Ambiental: um levantamento em empresas localizadas no Município de Montes Claros/MG. Prêmio Excelência Acadêmica. XII SemeAd. Empreendedorismo e Inovação. EAD. USP. 27 e 28 de agosto de 2009.2 Disponível em: http://www.fucape.br/premio_excelencia_academica/upld/trab/9/scheila.pdf. Acessado em: 29/08/2015. 20 Idem. 
De qualquer maneira, os passivos ambientais ocasionados na mesma época das atividades praticadas, devem ser contabilizados pela própria empresa a fim de se quantificar o dano e se possibilitar sua obrigação, não sendo vinculada a valoração do montante à existência do passivo.

Quanto aos eventos passados, ocorridos em exercícios anteriores e que não possam ser atribuídos aos fatos subsequentes, diz-se que os ajustes financeiros devem ser acrescidos no balanço atual em curso, já que os resultados dos exercícios anteriores somente devem ser retificados se houver mudança no critério contábil, ou em casos de erro, mas, para todo caso, tal obrigação deve ser estimados, devendo ser efetuada pelas previsões contábeis presentes ${ }^{21}$.

O passivo ambiental, portanto, na ocorrência de uma desapropriação por descumprimento da função socioambiental da propriedade rural, estará presente, na medida em que o dano que determinou a tomada do imóvel pelo Poder Público deverá ser assumido pelo novo proprietário, o qual assumirá a obrigação de indenizar a coletividade ou de recompor a área.

\section{A POSIÇÃO dO INSTITUTO NACIONAL DE COLONIZAÇÃO E REFORMA AGRÁRIA - INCRA SOBRE A DEDUÇÃO DO PASSIVO AMBIENTAL E A JUSTA INDENIZAÇÃO}

Quando se fala em desapropriação do imóvel rural, sabe-se que a competência instituída pela Constituição Federal de 1988 atribui à União, nos termos do artigo 184, a possibilidade de se desapropriar o imóvel que não esteja cumprindo sua função social, para fins de reforma agrária, mediante prévia e justa indenização em títulos da dívida agrária.

O Instituto Nacional de Colonização e Reforma Agrária - INCRA, por sua vez, é uma autarquia federal cuja missão fundamental é executar a reforma agrária e realizar o reordenamento fundiário nacional ${ }^{22}$.

Criado pelo Decreto 1.110, de 09 de julho de 1970, o INCRA é o resultado da união do extinto Instituto Brasileiro de Reforma Agrária - IBRA, do Instituto Nacional de Desenvolvimento Agrário - INDA e do Grupo Executivo da Reforma Agrária -

\footnotetext{
${ }^{21}$ Idem.

22 Informação disponível no sítio do INCRA: http://www.incra.gov.br/content/o-incra. Acesso em 01/09/2015
} 
GERA $^{23}$.

Segundo as próprias diretrizes do Instituo, essa autarquia é responsável pela implementação da reforma agrária, fiscalizando a função social dos imóveis rurais, contribuindo para a capacitação dos (as) assentados (as), o fomento da produção agroecológica de alimentos e a inserção nas cadeias produtivas ${ }^{24}$.

Assim, em se verificando a violação da função socioambiental da propriedade rural, a União, nos termos do artigo 184 da Constituição Federal em vigência, promoverá a desapropriação do imóvel em questão.

Entretanto, a questão que torna citado procedimento mais ou menos prolongado no tempo se refere ao quantum da indenização a ser repassada ao antigo proprietário do imóvel.

Conforme lições de Eduardo García de Enterría e Tomás Ramón Fernández ${ }^{25}$, "o bem expropriado se converte em seu valor econômico, que permanece no patrimônio do expropriado".

Sobre o mesmo tema, Luiz Guilherme Muller Prado ${ }^{26}$, citando lições de Manoel de Oliveira Franco Sobrinho, ressalta que:

\begin{abstract}
Afirma ele que o conteúdo da indenização, para que esta seja compensatória, contém materialmente um equivalente econômico (que responde pela situação real da coisa expropriada), indiretamente uma reparação do interesse (que se funda na consideração das vantagens desfrutadas pelo expropriado), a desvalorização da moeda (os índices estimativos devem ser os de capacidade aquisitiva não só em face do mercado de preços, mas também em razão dos progressivos aumentos nominais), a estimação da coisa para efeitos fiscais (não é um dado de grande importância, pois a incidência tributária muitas vezes não reflete exação por parte da Administra Pública, servindo apenas como ponto de partida), o seu estado de conservação e segurança (que são elementos relativos, devendo ser computados na formação do preço do ponto de vista da deterioração e da estabilidade) e as medidas econômicas corretivas (são aquelas que operam sobre a compensação indenizatória resguardada o expropriado da demora e outros fenômenos incidentes no processo, desde o momento em que se baixa o ato declaratório) ${ }^{27}$.
\end{abstract}

23 Artigo $2^{\circ}$, Decreto-Lei 1.110, de 09 de julho de 1970. Disponível em: http://www.planalto.gov.br/ccivil_03/decreto-lei/1965-1988/Del1110.htm. Acessado em 01/09/0215.

${ }^{24}$ Diretrizes e Estratégias para a Implementação da Reforma Agrária. Disponível em: http://www.incra.gov.br/content/o-incra. Acessado em: 01/09/2015.

${ }_{25}$ GARCÍA DE ENTERRÍA, Eduardo; FERNÁNDEZ, Tomás Ramon. Curso de derecho administrativo. $2^{\text {a }}$ Ed. Civitas. Madrid. 1982.

${ }_{26}$ PRADO, Luiz Guilherme Muller. A justa indenização na desapropriação do imóvel rural. São Paulo: Revistas dos Tribunais. 2007.

27 FRANCO SOBRINHO, Mano de Oliveira. Desapropriação: na doutrina, no direito brasileiro, na legislação comparada. São Paulo: Saraiva, 1973. In PRADO, Luiz Guilherme Muller. A justa indenização na desapropriação do imóvel rural. São Paulo: Revistas dos Tribunais. 2007. 
Todos esses requisitos, por sua vez, não devem ser analisados separadamente ${ }^{28}$, sob pena de se causar injustiças e desvios da justa indenização.

A avaliação do imóvel a ser desapropriado pelo Poder Público também tem certas particularidades inerentes à situação exposta, vez que no imóvel, em observância do artigo 12, da Lei 8.629/1993, devem ser observados diversos itens para a quantificação da justa indenização que reflita o preço de mercado do imóvel desapropriado em sua totalidade, dentre os quais se destacam: localização do imóvel, aptidão agrícola, dimensão do imóvel, funcionalidade, tempo de uso e estado de conservação das benfeitorias ${ }^{29}$.

$\mathrm{Na}$ avaliação do imóvel rural, portanto, além dos fatores que aumentam o valor, de ordem geral, deve ser levada em consideração a destinação normal da propriedade; a classificação e utilização das terras; as áreas de matas, pastagens e culturas; as atividades agrárias, pastoris ou extrativas que se realizam na gleba; as benfeitorias; a distância das terras aos centros urbanos; os meios de comunicação e transporte que servem o imóvel e as demais potencialidades do bem expropriado ${ }^{30}$, dependendo, de todo modo, dos casos em discussão.

É bem verdade que haverá imóveis que não terão o mesmo valor de indenização que outros, a partir de suas características inerentes, ou mesmo as áreas preservadas pelo antigo proprietário, as quais, também, deverão ser levadas em consideração na quantificação da indenização, considerando os passivos existentes.

Nesse sentido é que o Tribunal de Contas da União, em um caso de desapropriação de imóvel rural que descumpriu a sua função socioambiental, analisou supostos fatos de irregularidade na avaliação do passivo ambiental, na vistoria e na avaliação do imóvel em questão, prolatando o Acórdão 1362/2004.

Citada decisão foi um marco para as posteriores avaliações dos passivos ambientais e dos imóveis analisados num procedimento desapropriatório, a partir de preceitos pré-estipulados, determinando-se que o INCRA deduzisse o passivo ambiental, para que haja a correta responsabilização do poluidor/desapropriado, vez que esse causou o dano ambiental, evitando, por conseguinte, enriquecimento ilícito.

No respectivo Acórdão, a Corte de Contas assim discorreu:

\footnotetext{
${ }^{28}$ Idem.

29 BRASIL, Lei 8.629, de 25 de fevereiro de 1993. Artigo 12 e incisos. Disponível em: http://www.planalto.gov.br/ccivil_03/LEIS/L8629.htm. Acessado em: 01/09/2015.

${ }^{30}$ MEIRELLES, Hely Lopes. Direito administrativo brasileiro. 24. ed. Malheiros. São Paulo. 1999.
} 


\begin{abstract}
O INCRA tem o direito de ou receber o bem incólume (sem o passivo ambiental) ou obter a recuperação do passivo ambiental pelo desapropriado ou ressarcir-se dos valores despendidos na recuperação ambiental ou descontar do valor da desapropriação o valor correspondente ao ressarcimento. Por essa razão, nem se encontrando o imóvel incólume, nem tendo o imóvel sido recuperado pelo expropriado, deve o INCRA descontar o valor correspondente à recomposição ambiental do valor da indenização, para que seja justo, como exige a Constituição. Não o fazendo terá que, irrazoavelmente, posteriormente, acionar novamente o Judiciário para rever o valor despendido na recomposição ambiental, sob o risco de arcar com o ônus da reparação de ilícito que não cometeu ${ }^{31}$
\end{abstract}

Em não se levando em consideração o estipulado pelo Tribunal de Contas da União, estar-se-ia possibilitando inúmeras situações as quais destoam completamente com os princípios que norteiam a relação homem-natureza.

No caso analisado pelo TCU, verifica-se que o próprio INCRA-MT indenizou, como benfeitoria, portanto, em dinheiro, um dano ambiental existente no imóvel desapropriado. Ora, se o princípio do poluidor-pagador estipula, em suma, que aquele quem polui é o responsável pela sua reparação, não há como subsistir tal procedimento adotado pelo INCRA.

Deste modo, portanto, a relação do passivo ambiental com a propriedade desapropriada é bem mais profunda do que imaginamos, tendo em vista que, embora esse não tenha uma relação constante com fatos negativos, todo passivo deve ser levado em consideração quando da quantificação da indenização pela desapropriação.

O TCU, defendendo a posição de possibilidade de desconto do passivo ambiental, ressaltou que esse já compunha o patrimônio negativo do expropriado anteriormente à desapropriação. É que o valor do bem expropriado é obtido pela soma dos ativos que compõe o imóvel, subtraída dos passivos incorporados ao mesmo (o valor do imóvel é a soma do valor da terra nua, mais as benfeitorias e menos os passivos). Caso o INCRA indenize, computando apenas os ativos vinculados ao imóvel, estará enriquecendo sem causa o expropriado ${ }^{32}$.

Tal posição, por sua vez, é a que parece mais congruente com os preceitos do direito ambiental e agrário, bem como com a própria mentalidade sustentável que se instalou nas últimas décadas.

Após tal determinação, o INCRA passou, então, posicionar-se no sentido de descontar o valor do passivo na indenização da desapropriação, cumprindo com os

\footnotetext{
31 TRIBUNAL DE CONTAS DA UNIÃO. Acórdão 1362/2004 - Plenário. AC-1362-33/04-P. Disponível em: http://contas.tcu.gov.br/portaltextual/ServletTcuProxy. Acessado em: 01/09/2015.

32 TRIBUNAL DE CONTAS DA UNIÃO. Acórdão 1362/2004 - Plenário. AC-1362-33/04-P. Disponível em: http://contas.tcu.gov.br/portaltextual/ServletTcuProxy. Acessado em: 01/09/2015.
} 
preceitos e a dinâmica sustentável que norteiam toda a relação do homem com a propriedade rural, sem olvidar-se com o contido em nossa Constituição ${ }^{33}$.

Ocorre que tal posicionamento, embora estipulado pelo Tribunal de Contas da União, não está sendo aplicado uniformemente pelos Tribunais Regionais Federais, resultando em insegurança e divergências jurisprudenciais.

\section{A POSSIBILIDAdE DE DEDUÇÃO DO PASSIVO AMBIENTAL À LUZ DA JURISPRUDÊNCIA DO TRF-1 ${ }^{\circ}$ REGIÃO}

Superadas as discussões acerca da existência e consideração do passivo ambiental como fundamento de desconto da indenização pela desapropriação do imóvel rural que descumpriu sua função socioambiental.

Delineadas, também, a posição atual do Tribunal de Contas da União em se descontar da indenização o passivo existente na imóvel desapropriado, penalizando o poluidor, atendendo aos princípios do direito ambiental e ao próprio desenvolvimento sustentável, observa-se, de outro modo, que o Tribunal Regional da $1^{\text {a }}$ Região não estabeleceu uma posição sedimentada quanto sua possibilidade de dedução.

Cumpre ressaltar que se optou pela análise das decisões do Tribunal Regional Federal da $1^{\text {a }}$ Região em razão de sua competência abranger, sobretudo, todos os Estados da região Norte do país, a qual possui grande parte de sua área coberta pela Amazônia Legal, além de concentrar grande riqueza de biodiversidade, em decorrência de suas características regionais.

É de se destacar que o Tribunal de Contas da União, nos autos do Acórdão 1362/2004, caso em que houve indícios de irregularidades pelo INCRA-MT em processos de desapropriação, deixou claro que o desconto do passivo ambiental na indenização em favor do desapropriado não implica em descumprimento do princípio da justa indenização ${ }^{34}$, em cumprimento do artigo 12, da Lei 8.629/1993, o qual preceitua que “Considera-se justa a indenização que permita ao desapropriado a reposição, em seu patrimônio, do valor do bem que perdeu por interesse social".

\footnotetext{
${ }^{33}$ CIRNE, Mariana Barbosa. O passivo ambiental e o plano de manejo: O diálogo entre o direito ambiental e o agrário sobre o pagamento da justa indenização em desapropriação para fins de reforma agrária. Artigo disponível em: http://www.conpedi.org.br/manaus/arquivos/anais/fortaleza/3402.pdf. Acessado em 30/07/2015.

34 TRIBUNAL DE CONTAS DA UNIÃO. Acórdão 1362/2004 - Plenário. AC-1362-33/04-P. Disponível em: http://contas.tcu.gov.br/portaltextual/ServletTcuProxy. Acessado em: 01/09/2015.
} 
Por uma posição lógica, tem-se que o passivo ambiental, sendo a obrigação assumida pela empresa decorrente de um dano ambiental ocasionado pela execução de suas atividades já compõe o patrimônio negativo do proprietário, vez que está inserido na propriedade, bem como o valor dessa corresponde aos ativos, somando-se às terras nuas e benfeitorias, diminuído dos passivos existentes ${ }^{35}$.

Dessa forma, se o Instituto de Colonização e Reforma Agrária não descontar os passivos existentes do imóvel desapropriado do valor da indenização, de acordo com o Tribunal de Contas da União, haverá, como consequência, o enriquecimento sem causa o desapropriado, já que será toda a coletividade quem irá arcar com os resultados desse passivo.

Nessa esteira de raciocínio, o Tribunal Regional Federal da $1^{\mathrm{a}}$ Região, desde quando se iniciaram as questões relacionadas à existência do passivo ambiental nas propriedades a serem desapropriadas pelo Poder Público, não firmou uma posição sedimentada, a qual pudesse uniformizar as decisões e o próprio posicionamento do colegiado em questão.

Observa-se que, embora haja os diversos princípios de direito ambiental e agrário que regem a relação do homem com a propriedade rural, decisões que sustentam a impossibilidade de desconto do valor do passivo ambiental pelo INCRA, em razão da violação do princípio da justa indenização, não se coadunam com o caráter eminentemente protecionista dos direitos fundamentais que tomou nossa Constituição Federal de 1988, estipulando que o meio ambiente equilibrado é essencial para a sadia qualidade de vida, equiparando-o aos demais direitos fundamentais.

É nessa linha de raciocínio que o Tribunal Regional Federal da $1^{\text {a }}$ Região, pela Terceira Turma, defendeu a ideia de que há possibilidade de dedução do passivo ambiental na indenização em razão da desapropriação, conforme julgamento recente, na qual se constatou que o perito oficial confirmou a efetiva revegetação levada a efeito pelo INCRA no imóvel expropriado, com o fim de recompor a reserva legal, o que permite a dedução da importância mensurada pela Autarquia a título de passivo ambiental, do valor arbitrado para a indenização da terra nua ${ }^{36}$.

Entretanto, essa mesma terceira turma, em outra situação semelhante, deixou claro que não é cabível o abatimento unilateral da parcela relativa ao passivo ambiental

\footnotetext{
${ }^{35}$ Idem.

${ }^{36}$ AC: 74658120094014300 Relatores: DESEMBARGADOR FEDERAL MÁRIO CÉSAR RIBEIRO, Data de Julgamento: 05/08/2014, TERCEIRA TURMA, Data de Publicação: 15/08/2014.
} 
do valor da indenização a ser depositado por ocasião do ajuizamento da ação expropriatória $^{37}$.

Afirmou-se que, quando da desapropriação para fins de reforma agrária do imóvel que não estiver cumprindo sua função social, a indenização correspondente, ou seja, o depósito da oferta da terra nua deve ser feito integralmente, sem nenhuma dedução a título de passivo ambiental ${ }^{38}$.

Seguindo essa mesma linha de raciocínio, as decisões AC 200633000206884, Desembargadora Federal Monica Sifuentes, TRF1 - Terceira Turma, e-DJF1, Data: 17/01/2014, página 87; AC 200539010006080, Desembargadora Federal Monica Sifuentes, TRF1 - Terceira Turma, e-DJF1, Data: 21/03/2014, página 385; AG, Desembargador Federal Hilton Queiroz, TRF1 - Quarta Turma, e-DJF1, Data: 29/04/2014, página 181, rechaçam a possibilidade de dedução do passivo ambiental na indenização da desapropriação da propriedade rural.

Tal entendimento é embasado na tese de que não pode haver a dedução sobre a indenização, em função de que a parte expropriada já sofre a desvalorização de seu imóvel justamente por haver a degradação ambiental, não podendo custear o ônus da recuperação da referida área com a dedução.

Diante dessa divergência existente no mesmo Tribunal, é de se ressaltar que há de ser pacificado o entendimento que mais se coaduna com os princípios de direito ambiental, com o entendimento refletido em nossa Carta Magna e, ainda, com a própria consciência ambientalista que a sociedade tem assumido nas últimas décadas.

\section{CONCLUSÃO}

Como visto, ausente o desconto do passivo ambiental no valor de indenização da desapropriação, haverá, como consequência, a responsabilização indireta da própria coletividade, pela recomposição daquele passivo.

Imagine-se, por exemplo, um imóvel rural que descumpriu sua função socioambiental, tendo desmatado e ocasionado inúmeros danos de ordem ambiental. Tal propriedade, como consequência lógica, estará sujeita á desapropriação pelo Poder

\footnotetext{
${ }^{37}$ AG 00276402220144010000, JUÍZA FEDERAL LILIAN OLIVEIRA DA COSTA TOURINHO (CONV.), TRF1 - TERCEIRA TURMA, e-DJF1 DATA: 15/05/2015. PÁGINA: 751;

38 AC: 3041320094013300 BA 0000304-13.2009.4.01.3300, Relator: DESEMBARGADOR FEDERAL CÂNDIDO RIBEIRO, Data de Julgamento: 10/12/2013, TERCEIRA TURMA, Data de Publicação: eDJF1 p.1070, 
Público, por interesse social para fins de reforma agrária. Por sua vez, a reforma agrária tem como seus fundamentos, o bem estar social e a justiça social, a partir da justa distribuição de terras e para condicionar o uso desta aos bem estar da coletividade ${ }^{39}$.

Desta feita, tal propriedade desapropriada será destinada aos grupos necessitados, às famílias que não possuem uma propriedade sequer. A partir da inserção dessas famílias nos imóveis desapropriados, nos quais não se descontou os passivos ambientais ali existentes, duas opções surgirão: a uma, o INCRA arcará com os custos de recomposição da área degradada; a duas, as famílias que ocuparão as respectivas propriedades assumirão o risco e a responsabilidade de se recompor e manter em níveis satisfatórios a existência dos recursos naturais.

De todo modo, diante dessas duas opções, tem-se que, no final das contas, será a própria coletividade quem suportará todos os custos pelo desgaste e pelo uso irresponsável e irregular da propriedade rural.

Para a posição que defende a impossibilidade de dedução do passivo ambiental no valor da desapropriação, sustenta, em suma, que haverá violação do princípio da justa indenização. Ora, citado princípio, por Arruda Alvim ${ }^{40}$, traduz-se na ideia de exata substituição do bem expropriado pelo seu valor equivalente, dando-se pelo imóvel em questão o mesmo quantum que o mesmo valha no mercado. É nesse ponto que reside a grande discussão acerca da desapropriação.

De outra banda, tendo em vista que o passivo ambiental, como afirmado alhures, pode decorrer de ações de conotação negativa e positiva para o meio ambiente, sendo que, quanto às negativas, o sujeito poluidor estará sujeito a sofrer a irrupção em sua propriedade pelo Poder Público.

Assim, existirão os passivos ambientais, os quais, como no próprio entendimento do TCU, já farão parte do próprio valor do imóvel rural, não havendo que se falar em violação ao princípio da justa indenização.

Como bem afirma Vicente de Paula Mendes ${ }^{41}$ :

\footnotetext{
${ }^{39}$ MAGALHÃES, José Luiz Quadros de. Reforma Agrária no Brasil. Rev. Inf. Legisl. Brasília, 25. n. 100. $\quad$ Out/Dez. $1988 . \quad$ Disponível $\quad$ em: http://www2.senado.leg.br/bdsf/bitstream/handle/id/181893/000442097.pdf?sequence=1. Acessado em: 01/09/2015.

${ }^{40}$ ARRUDA, Alvim. Desapropriação, indenização e valor corrigido. Revista de Direito Público, v. 14. São Paulo, Out-Dez. 1970.

${ }^{41}$ MENDES, Vicente de Paula. A indenização na desapropriação: doutrina, legislação e jurisprudência. Belo Horizonte: Del Rey,. 1992.
} 


\begin{abstract}
A justa indenização, pois, tanto poderia resultar de processo de recomposição integral do patrimônio do proprietário, como de recomposição parcial, dependendo dos critérios e valores aceitos pela lei e pelo juiz. Mas não se pode confundir integral com justa, ou parcial com injusto.
\end{abstract}

Destarte, a justa indenização estará fielmente cumprida quando o real valor do imóvel for repassado ao particular que sofreu a desapropriação, motivo pelo qual, nada mais justo que repassar-lhe o preço equivalente já com a dedução do passivo ambiental existente em sua propriedade.

É desse modo, no entanto, que o Tribunal Regional Federal da $1^{\mathrm{a}}$ Região deveria manifestar seu entendimento, por mais que a própria Constituição preveja a prévia e justa indenização ao proprietário que sofrerá a desapropriação, o passivo ambiental, por integrar o valor do imóvel, merece ser descontado efetivamente do valor dessa indenização.

Portanto, na atual realidade em que se encontra nossa sociedade, impõe-se a necessidade de se pacificar tais decisões, a fim de se evitar que a insegurança jurídica, antagônica aos próprios preceitos constitucionais, prevaleça sobre bens maiores que estão em discussão, sobretudo aqueles imprescindíveis à sadia qualidade de vida, fundamental para nossas comunidades contemporâneas.

\title{
REFERÊNCIAS
}

ARRUDA, Alvim. Desapropriação, indenização e valor corrigido. Revista de Direito Público, v. 14. São Paulo, Out-Dez. 1970.

BORGES, Roxana Cardoso Brasileiro, "Função ambiental da propriedade e reforma agrária", in SILVEIRA, Domingos Sávio Dresch; XAVIER, Flávio Sant'Anna. O Direito Agrário em debate. Porto Alegre: Editora Livraria do Advogado, 1998.

CIRNE, Mariana Barbosa. O passivo ambiental e o plano de manejo: O diálogo entre o direito ambiental e o agrário sobre o pagamento da justa indenização em desapropriação para fins de reforma agrária. Artigo disponível em: http://www.conpedi.org.br/manaus/arquivos/anais/fortaleza/3402.pdf. Acessado em 30/07/2015.

COELHO, Dutra, et al.. Evidenciação do investimento no social e no ambiental. Revista Pensar Contábil ano III, $\mathrm{n}^{\circ} 09$ agosto/outubro de 2000. In FERREIRA (2006), REBOLLO (2000) e CASTRO (2006) in FERNANDES, Sheila Mendes; SANTIAGO, Wagner de Paulo; PEIXOTO. Fernanda Maciel. Passivo Ambiental: um levantamento em empresas localizadas no Município de Montes Claros/MG. Prêmio Excelência Acadêmica. XII SemeAd. Empreendedorismo e Inovação. EAD. USP. 27 e 28 de agosto de

2009.

Disponível

em: 
http://www.fucape.br/premio_excelencia_academica/upld/trab/9/scheila.pdf. Acessado em: $29 / 08 / 2015$.

Diretrizes e Estratégias para a Implementação da Reforma Agrária. Disponível em: http://www.incra.gov.br/content/o-incra. Acessado em: 01/09/2015.

FERREIRA (2006), REBOLLO (2000) e CASTRO (2006) in FERNANDES, Sheila Mendes; SANTIAGO, Wagner de Paulo; PEIXOTO. Fernanda Maciel. Passivo ambiental: Um levantamento em empresas localizadas no Município de Montes Claros/MG. Prêmio Excelência Acadêmica. XII SemeAd. Empreendedorismo e Inovação. EAD. USP. 27 e 28 de agosto de 2009. Disponível em: http://www.fucape.br/premio_excelencia_academica/upld/trab/9/scheila.pdf. Acessado em: 23/08/2015.

FRANCO SOBRINHO, Mano de Oliveira. Desapropriação: na doutrina, no direito brasileiro, na legislação comparada. São Paulo: Saraiva, 1973. In PRADO, Luiz Guilherme Muller. A justa indenização na desapropriação do imóvel rural. São Paulo: Revistas dos Tribunais. 2007.

GARCÍA DE ENTERRÍA, Eduardo; FERNÁNDEZ, Tomás Ramon. Curso de derecho administrativo. $2^{\text {a }}$ Ed. Civitas. Madrid. 1982.

KRAEMER, Maria Elisabeth Pereira. Passivo ambiental. Artigo publicado e disponível no site: http://www.amda.org.br/imgs/up/Artigo_21.pdf. Acessado em: $14 / 08 / 2015$. 